\title{
Inhibition of $\beta$-catenin signaling by phenobarbital in hepatoma cells in vitro
}

\author{
Nicola Groll ${ }^{\mathrm{a}}$, Tamara Petrikat ${ }^{\mathrm{b}}$, Silvia Vetter ${ }^{\mathrm{b}}$, Christine Wenz ${ }^{\mathrm{b}}$, Joern Dengjel ${ }^{\mathrm{d}}$, \\ Christine Gretzmeier ${ }^{\mathrm{e}}$, Frederik Weiss ${ }^{\mathrm{a}}$, Oliver Poetz ${ }^{\mathrm{a}}$, Thomas O. Joos ${ }^{\mathrm{a}}$, \\ Michael Schwarz ${ }^{\mathrm{b}}$, Albert Braeuning ${ }^{\mathrm{b}, \mathrm{c}, *}$
}

\author{
a Natural and Medical Sciences Institute at the University of Tübingen, Markwiesenstr. 55, 72770 Reutlingen, Germany \\ ${ }^{\mathrm{b}}$ University of Tübingen, Dept. of Experimental and Clinical Pharmacology and Toxicology, Wilhelmstr. 56, 72074 Tübingen, Germany \\ ${ }^{c}$ Federal Institute for Risk Assessment, Dept. Food Safety, Max-Dohrn-Str. 8-10, 10589 Berlin, Germany \\ d University of Fribourg, Dept. of Biology, Chemin du Musée 10, 1700 Fribourg, Switzerland \\ e University of Freiburg, Center for Biological Systems Analysis, Habsburgerstr. 49, 79104 Freiburg, Germany
}

\begin{abstract}
The antiepileptic drug phenobarbital (PB) exerts hepatic effect based on indirect activation of the constitutive androstane receptor (CAR) via inhibition of the epidermal growth factor receptor (EGFR) and the kinase Src. It has furthermore been observed that in mice PB suppresses the growth of hepatocellular carcinoma with overactive signaling through the oncogenic Wnt/ $\beta$-catenin pathway, thus suggesting an interference of PB with $\beta$-catenin signaling. The present work was aimed to characterize effects of PB on $\beta$-catenin signaling at different cellular levels and to elucidate molecular details of the interaction of PB and $\beta$-catenin in an in vitro system of mouse hepatoma cells. PB efficiently inhibited signaling through $\beta$-catenin. This phenomenon was in-depth characterized at the levels of $\beta$-catenin protein accumulation and transcriptional activity. Mechanistic analyses revealed that the effect of PB on $\beta$-catenin signaling was independent of the activation of CAR and also independent of the cytosolic multi-protein complex responsible for physiological post-translation control of the $\beta$-catenin pathway via initiation of $\beta$-catenin degradation. Instead, evidence is provided that PB diminishes $\beta$-catenin protein production by inhibition of protein synthesis via signal transduction through EGFR and Src. The proposed mechanism is well in agreement with previously published activities of PB at the EGFR and Src-mediated regulation of $\beta$-catenin mRNA translation. Inhibition of $\beta$-catenin signaling by PB through the proposed mechanism might explain the inhibitory effect of $\mathrm{PB}$ on the growth of specific sub-populations of mouse liver tumors. In conclusion, the present data comprehensively characterize the effect of $\mathrm{PB}$ on $\beta$-catenin signaling in mouse hepatoma cells in vitro and provides mechanistic insight into the molecular processes underlying the observed effect.
\end{abstract}

\section{Introduction}

Phenobarbital (PB) is an antiepileptic drug due to its interference with $\gamma$-aminobutyric acid (GABA)-dependent neurotransmission (Macdonald and McLean, 1986). PB is capable of inducing tumors in rodents by a non-genotoxic mechanism via activation of the constitutive androstane receptor (CAR) and also involving cellcell communication via the gap junction protein connexin 32 (Cx32) (Moennikes et al., 2000; Yamamoto et al., 2004). For a

* Corresponding author at: German Federal Institute for Risk Assessment, Dept. Food Safety, Max-Dohrn-Str. 8-10, 10589, Berlin, Germany.

E-mail address: Albert.Braeuning@bfr.bund.de (A. Braeuning). detailed overview of the toxicological properties of PB please refer to IARC (2001). Human relevance of tumorigenicity of PB through CAR activation is subject of an ongoing controversial debate (Braeuning, 2014; Braeuning et al., 2014, 2015; Braeuning and Schwarz, 2016; Elcombe et al., 2014; Yamada et al., 2014).

Despite decades of research on PB effects and CAR activation, the mechanism for the indirect activation of CAR by PB had not been elucidated until a few years ago (Mutoh et al., 2013): PB activates CAR via inhibition of the epidermal growth factor receptor (EGFR). This leads to diminished activity of the kinase Src, which in turn impacts on the phosphorylation of RACK1, thus enabling non-phosphorylated RACK1 to activate protein phosphatase 2A (PP2A) leading to dephosphorylation of CAR. Non- 
phosphorylated CAR then translocates to the nucleus and initiates pleiotropic transcriptional responses related to hepatocyte proliferation, hypertrophy and apoptosis, but also to xenobiotic metabolism and energy homeostasis. Cellular functions of CAR have e.g. been reviewed by Qatanani and Moore (2005) and by Whysner et al. (1996).

While chronic administration of $\mathrm{PB}$ to mice promotes the outgrowth of certain particular hepatoma sub-populations under appropriate experimental conditions, other tumor sub-populations, characterized by their individual tumorigenesis-driving genomic mutations and corresponding gene expression profiles, are significantly inhibited by $\mathrm{PB}$ in their growth, thus making the substance more a tumor selector than a tumor promoter (Braeuning and Schwarz, 2016): the formation of hepatocellular carcinoma (HCC) driven by pronounced activation of the canonical Wnt/ $\beta$-catenin signaling pathway is inhibited by PB in a mouse model of hepatic APC (adenomatous polyposis coli protein) deficiency (Braeuning et al., 2016). Canonical Wnt/ $\beta$-catenin signaling is one of the most prominent oncogenic signaling cascades and frequently activated in human as well as rodent tumors. Genomic alterations in different critical components of the cascade, for example in Ctnnb1 (encoding $\beta$-catenin) or $A p c$ (encoding a negative regulator of $\beta$-catenin) lead to constitutive activation of the pathway. This contributes to tumor growth by triggering the expression of downstream target genes related to proliferation and tumorigenesis as reviewed by Lustig and Behrens (2003). Physiologically, the activity of the pathway is mainly regulated by post-translational modifications of $\beta$-catenin which impact on the degradation of the protein: phosphorylation of $\beta$-catenin at residues near the $\mathrm{N}$-terminus by a cytosolic multiprotein complex which consists, amongst others, of APC and glycogen synthase kinase $3 \beta$ (GSK3 $\beta$ ), primes the protein for subsequent proteasomal degradation. This process is blocked by inhibition of GSK3 $\beta$ or the proteasome, or by Ctnnb1 mutations that eliminate the critical phosphorylation sites; inhibition of $\beta$-catenin degradation activates the pathway and leads to cytosolic accumulation and nuclear translocation of free, transcriptionally active $\beta$-catenin (Lustig and Behrens, 2003). Of note, $\beta$-catenin regulation might also occur via altered transcription of the Ctnnb1 gene (Gosens et al., 2010). Interestingly, the HCC from the abovementioned mouse model are defective in $\beta$-catenin degradation due to their lack of functional APC, but additionally exhibit strongly increased Ctnnb1 mRNA levels which also seem to contribute to $\beta$-catenin activation in this particular tumor type (Braeuning et al., 2016). Another mechanism of regulation is via enhanced translation of Ctnnb1 mRNA, a process which is mediated by Src kinase which phosphorylates the eukaryotic initiation factor $4 \mathrm{E}$ via extracellular signal-regulated kinase (ERK)-dependent signaling and thus regulates $\beta$-catenin protein levels by altering its synthesis, not its degradation (Karni et al., 2005). Moreover, mouse liver tumors with activated mitogen-activated protein kinase (MAPK)/ERK signaling due to activating mutations in the $\mathrm{Ha}$-ras proto-oncogene upstream of ERK are also efficiently inhibited by PB (Aydinlik et al., 2001; Moennikes et al., 2000).

HCC from the APC-deficient mouse model described above are repressed by PB despite an almost complete lack of CAR expression (Braeuning et al., 2016). Moreover, MAPK-activated mouse liver tumors exhibit reduced expression of CAR, as compared to normal hepatocytes (Jaworski et al., 2007), and react less sensitive to PB stimulation with regard to the induction of CAR target genes related to xenobiotic metabolism (own unpublished data). It thus appears likely that CAR-independent effects mediate at least some of the tumor-inhibitory effects of PB. As tumor growth is driven by specific oncogenic signaling cascades, it appears plausible that $\mathrm{PB}$ might interfere with such cellular signal transduction pathways to inhibit the growth of certain tumor sub-populations. Interestingly, data from a recent publication on PB inhibition of calpains, a family of proteases, suggest an inhibition of $\beta$-catenin signaling by PB (Groll et al., 2016a).

Therefore, this study was designed to provide an in-depth analysis of the effects of PB on Wnt $/ \beta$-catenin signaling in mouse hepatoma cells in vitro and to unravel the underlying molecular mechanisms.

\section{Material and methods}

\subsection{Cell culture and treatment}

Mouse hepatoma cells from line 70.4 (Groll et al., 2016a; Kress et al., 1992), stably transfected with the $8 \times \beta$-catenin/TCF-driven SuperTopFlash (STF) luciferase reporter vector (Braeuning et al., 2007), and a 70.4-derived sub-clone stably transfected with a doxycycline-inducible system for the expression of mutant, constitutively active human $\beta$-catenin ${ }^{\mathrm{S} 33 \mathrm{Y}}$ (termed "70.4Mo"; Zeller et al., 2012) were cultivated in D-MEM/F12 medium supplemented with $10 \%$ fetal calf serum and antibiotics as previously described in the abovementioned publications. Identity of the cell line was routinely confirmed by genetic analyses of the pattern of mutations in different proto-oncogenes and tumor suppressor genes according to Aydinlik et al. (2001), Jaworski et al. (2005), and Kress et al. (1992). Mouse hepatoma cells from line 55.1c stably transfected with the STF reporter, Hepa1c1c7 mouse hepatoma cells, and human HepG2 hepatoma cells were cultivated under standard conditions as previously described (Braeuning and Vetter, 2012; Luckert et al., 2016). Cells were seeded $24 \mathrm{~h}$ prior to treatment. Treatment was performed with $3 \mathrm{mM}$ PB (PB sodium; dissolved in $\mathrm{H}_{2} \mathrm{O}$; Sigma, Taufkirchen, Germany), $1 \mu \mathrm{M}$ MG132 (dissolved in dimethyl sulfoxide (DMSO); Enzo Life Sciences, Lausen, Switzerland), $15 \mathrm{mM} \mathrm{LiCl}$ (in $\mathrm{H}_{2} \mathrm{O}$; Carl Roth, Karlsruhe, Germany), $5 \mu \mathrm{M}$ bortezomib (in DMSO; LC Laboratories, Woburn, MA, USA), $1 \mu \mathrm{g} / \mathrm{mL}$ doxycycline (in $\mathrm{H}_{2} \mathrm{O}$; Sigma), $20 \mu \mathrm{M}$ iCRT3 (in DMSO; Sigma), $10 \mu \mathrm{M}$ TCPOBOP (1,4-Bis-[2-(3,5-dichloropyridy-

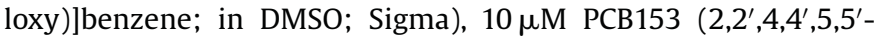
hexachlorobiphenyl; in DMSO; synthesized as described in Rignall et al. (2013)), $2.5 \mu \mathrm{M}$ BAPTA/AM (in DMSO with 20\% pluronic 127; Sigma), $25 \mu$ M PD150606 (in DMSO; Sigma), $50 \mu M$ Calpain Inhibitor XI (in DMSO; Merck, Darmstadt, Germany), $10 \mu \mathrm{M}$ Src Inhibitor I (in DMSO; Sigma), $2 \mu \mathrm{M}$ gefitinib (in DMSO; Selleckchem, Munich, Germany), $2 \mu \mathrm{M}$ erlotinib (in DMSO; kindly provided by Dr. M. Toulany, University of Tübingen, Germany), $0.33 \mu \mathrm{M}$ cycloheximide (in DMSO; Sigma), $10 \mu \mathrm{M}$ saracatinib (in DMSO; Selleckchem), $20 \mu \mathrm{M}$ GABA (in $\mathrm{H}_{2} \mathrm{O}$; Sigma), or $10 \mathrm{nM}$ okadaic acid (in DMSO; Merck) for the time frames indicated. The choice of concentrations in the assays was based on previous use as extracted from the literature, and/or based on initial cytotoxicity testing with each substance. All compounds did not reduce viability of the cell lines used, as determined by use of the Alamar Blue and MTT cytotoxicity assays, and the highest non-cytotoxic concentration from the more sensitive of the two assays was chosen for treatment of cells.

\subsection{Transfection}

Cell transfection was performed by lipofection using Lipofectamine 2000 transfection reagent (Thermo Fisher Scientific, Waltham, MA, USA) as previously described (Schulthess et al., 2015). Cells were seeded $24 \mathrm{~h}$ prior to transfection and treated with the chemicals mentioned above starting $24 \mathrm{~h}$ after transfection. Signaling through $\beta$-catenin was monitored in HepG2, Hepa1c1c7, and 70.4Mo cells by transient transfection of the $\beta$-catenin/TCFdriven STF reporter vector (see Section 2.1). In stably STFtransfected 70.4 cells, Src kinase was transiently expressed from 
two different vectors encoding, under the control of the constitutively active cytomegaly virus (CMV) promoter, either mouse wildtype Src or a point-mutated (S177A) version of the protein with higher basal kinase activity (Kollmorgen et al., 2012). Control cells were transfected with the respective amount of empty vector backbone containing the CMV promoter but no Src cDNA. The plasmid pRL-CMV (Promega, Mannheim, Germany) providing CMV promoter-controlled expression of Renilla luciferase was transfected for normalization purposes in all transient transfection experiments.

\subsection{Luciferase reporter assay}

Firefly luciferase activities from stably STF-transfected 70.4 and 55.1c cells were determined in cells stably transfected with the SuperTopFlash reporter as previously described (Braeuning and Vetter, 2012). Luciferase values were normalized to cell vitality, as determined by use of the Alamar Blue assay. For transient transfections of 70.4Mo or HepG2 cells, a dual-luciferase assay was conducted and Firefly luciferase values were normalized to Renilla luciferase values as previously described (Schulthess et al., 2015). PB was checked for the absence of direct inhibition of the Firefly luciferase enzyme.

\subsection{Western blotting}

Total cell lysates were prepared by lysis of cells at $4{ }^{\circ} \mathrm{C}$ in lysis buffer $(150 \mathrm{mM} \mathrm{NaCl}, 50 \mathrm{mM}$ Tris pH 7.4, 1\% Triton-X-100, $1 \mathrm{x}$ Complete Protease Inhibitor cocktail (Roche, Mannheim, Germany), $1 \mathrm{x}$ phosphatase inhibitor cocktails II \& III (Sigma), and $1 \mathrm{U} / \mathrm{mL}$ benzonase DNAse (Merck)) for $30 \mathrm{~min}$ at $4{ }^{\circ} \mathrm{C}$ while mixing gently. The lysates were centrifuged at $100,000 \times g$ for $30 \mathrm{~min}$ at $4^{\circ} \mathrm{C}$. The supernatant was then transferred into a fresh tube and protein concentration was determined by use of the DC protein assay kit (Biorad, Munich, Germany) according to the manufacturer's protocol. $25 \mu \mathrm{g}$ protein per lane were separated by sodium dodecyl sulfate gel electrophoresis and transferred to nitrocellulose membranes using standard methodology. Ponceau S staining of Western blots was used to confirm equal loading of the individual lanes. Following incubation with a primary antibody directed against $\beta$-catenin (BD Biosciences, Franklin Lakes, NJ, USA; $1: 1,000$ dilution) and a HRPO-conjugated secondary antibody directed against mouse IgG (Dianova, Hamburg, Germany; 1:4,000), SuperSignal West Pico Substrate (Thermo Fisher Scientific, Waltham, MA, USA) was used for signal generation. Images were acquired using an ImageQuant LAS 4000 mini (GE Healthcare, Chalfont St. Giles, UK).

\subsection{Microsphere-based $\beta$-catenin assays}

The microsphere-based $\beta$-catenin assay for the detection of different molecular forms of $\beta$-catenin and for measuring proteinprotein interactions was performed as described previously (Groll et al., 2015a, 2015b). In brief, the $\beta$-catenin bead array panel employs antibodies and known interaction partners of $\beta$-catenin to study the phosphorylation status of the protein and its complexation status within the same multiplexed assay system. Differentially phosphorylated versions of $\beta$-catenin are measured by use of bead array-based sandwich immunoassays. By utilizing different antibodies directed against specifically phosphorylated versions of $\beta$-catenin (anti-non pSer33/Ser37/Thr41, anti-pSer33/ Ser37/Thr41, anti-pSer45, anti-pSer552 and anti-pSer675; all from Cell Signaling Technology, Cambridge, UK) and a single panspecific anti- $\beta$-catenin antibody (R\&D Systems, Wiesbaden, Germany) serving as the capture molecule, it is possible to reliably discriminate various phosphorylated $\beta$-catenin forms (Groll et al. 2015b).

The recombinantly expressed binding partners of $\beta$-catenin, ECT (E-cadherin cytosolic tail), ICAT (inhibitor of $\beta$-catenin), and TCF4 (T-cell factor 4) are used as bait proteins in protein-protein interaction assays for binding and detecting free cellular, transcriptionally active $\beta$-catenin. In all assay set-ups, the same antibody specific for the $\mathrm{C}$-terminus of $\beta$-catenin (BD Biosciences) is used as a detector. Generation of ECT-, ICAT-, and TCF-GST fusion proteins and their utilization in microsphere-based proteinprotein interaction assays have been described in detail previously (Groll et al., 2015a).

For analysis of potential disturbance of protein-protein interactions by PB, the abovementioned GST fusion proteins were immobilized on beads as described above and incubated with 0.1 $1 \mu \mathrm{g}$ of purified $\beta$-catenin protein (generated as described in Traenkle et al. (2015)) in assay buffer with up to $30 \mathrm{mM}$ PB for $1 \mathrm{~h}$. Subsequent measurement was conducted as described above.

\subsection{Pulsed SILAC assay and mass spectrometry}

De novo formation of $\beta$-catenin was monitored by metabolic labeling of $\beta$-catenin in 70.4 hepatoma cells by the pulsed stable isotopically labeling method as described by Schwanhausser et al. (2009). DMEM cell culture medium was prepared as described in the aforementioned publication using $28 \mathrm{mg} / \mathrm{L}^{13} \mathrm{C}^{15} \mathrm{~N} 4$ arginine plus $48 \mathrm{mg} / \mathrm{L}{ }^{13} \mathrm{C} 6{ }^{15} \mathrm{~N} 2$ lysine and $28 \mathrm{mg} / \mathrm{L}{ }^{13} \mathrm{C} 6$ arginine plus $48 \mathrm{mg} / \mathrm{L}$ D4 lysine (Euriso-Top, Saarbrücken, Germany) for heavy and medium-heavy medium, respectively. After lysis of the metabolically labeled cell cultures total protein levels were quantified using a bicinchinonic assay protocol (Thermo Fisher Scientific). $15 \mu \mathrm{g}$ protein extract of each treatment time point was mixed with the respective control. Enzymatic fragmentation was performed as described earlier (Groll et al., 2016b). A trypsin-toprotein ratio of $1: 10$ was applied. The $\beta$-catenin proteotypic peptide TSMGGTQQQFVEGVR was immunoprecipitated using an antibody generated towards the C-terminal sequence EVLR according to Weiss et al. (2015). The $\beta$-catenin synthesis rate was determined by measuring the newly synthesized metabolically labeled peptide variants ${ }^{13} \mathrm{C} 6$ and ${ }^{13} \mathrm{C}^{15} \mathrm{~N} 4$ using targeted Single-Ion-Monitoring (tSIM) on a QExactive ${ }^{\mathrm{TM}}$ Plus (Thermo Fisher Scientific). Raw data were evaluated using Pinpoint 1.4 (Thermo Fisher Scientific). Synthesis rate was determined by calculating the peak area ratio of both isotopically labeled peptide variants.

\subsection{Immunofluorescent staining}

Immunostaining of 70.4 cells fixed in ice-cold $4 \%$ aqueous formaldehyde solution for 5 min was performed by the use of a pan-specific antibody directed against $\beta$-catenin (BD Biosciences; $1: 250$ dilution; o/n incubation at $4{ }^{\circ} \mathrm{C}$ ) in combination with a Cy3labeled secondary antibody directed against mouse IgG (Dianova, Hamburg, Germany; 1:200 dilution; $2 \mathrm{~h}$ incubation at room temperature). Immunofluorescence images were recorded on a Zeiss Axiolmager microscope (Zeiss, Jena, Germany) at $40 \mathrm{x}$ magnification in combination with AxioVision software (Zeiss) at $\lambda_{\mathrm{exc}}=550 \mathrm{~nm}$ and $\lambda_{\mathrm{emm}}=570 \mathrm{~nm}$.

\subsection{Real-time RT-PCR}

Total RNA was isolated using Trizol (Thermo Fisher Scientific) and reverse transcribed by avian myeloblastosis reverse transcriptase (Promega) using standard methodology as previously published (Groll et al., 2016a). Real-time RT-PCR was conducted on a LightCycler instrument (Roche) using SYBR Green I-based 
detection according to the manufacturer's instructions as previously described (Groll et al., 2016a). The following primer pairs were used: Axin2 fwd 5'- CGACGCACTGACCGACGATT-3', Axin2 rev 5'- TCCAGACTATGGCGGCTTTCC-3'; CAR fwd 5'-AACAACAGTCTCGGCTCCAAA- $3^{\prime}$, CAR rev 5'-AGCATTTCATTGCCACTCCC3'; Ctnnb1 fwd 5'-GCGTGGACAATGGCTACTCAAG-3', Ctnnb1 rev 5'CCTGACCCTTTTCGGAACGAG-3'; CX32 fwd 5'CTTGTGCCTCTTTACCTCTTCC-3', CX32 rev 5'-ACAGCGTCTGCTATGACCATT-3'; Cyp2b10 fwd 5'-TACTCCTATTCCATGTCTCCAAA-3', Cyp2b10 rev 5'- TCCAGAAGTCTCTTTTCACATGT-3'; Cyp2c fwd 5'CTCCCTCCTGGCCCCAC-3', Cyp2c rev 5'-GGAGCACAGCTCAGGATGAA-3'; RXR $\alpha$ fwd 5'-ACATTGGGCTTCGGGACTGG-3', RXR $\alpha$ rev 5' CTTGTTGTCTCGGCAGGTGTAGGT-3'; $18 \mathrm{~s}$ rRNA fwd 5'-CGGCTACCACATCCAAGGAA-3', 18 s rRNA rev 5“-GCTGGAATTACCGCGGCT-3“; Gapdh fwd 5"-ACCACAGTCCATGCCATCAC-3', Gapdh rev 5'-TCCACCACCCTGTTGCTGTA- ${ }^{\prime}$; Actb fwd $5^{\prime}$-TCTGGCACCACACCTTCTACA$3^{\prime}$, Actb rev 5'-GGGGTGTTGAAGGTCTCAAAC-3'. Data were normalized based on the expression of the housekeeping gene and the respective PCR efficiencies according to the method described by Pfaffl (2001). 18 s rRNA was used as a housekeeping gene in all assays. In order to substantiate findings on reduced Axin2 expression by PB, normalization to Gapdh or Actb was performed in addition. The choice of the housekeeping gene did not impact on the observed down-regulation of Axin2 mRNA (not shown). For comparison, RNA from healthy liver tissue of an adult male wildtype mouse from a previous study (Ganzenberg et al., 2013) was used in some experiments.

\subsection{Src kinase activity assay}

For measurement of total cellular Src family kinase activity, cells were lysed on ice in lysis buffer $(150 \mathrm{mM} \mathrm{NaCl}, 10 \mathrm{mM}$ $\mathrm{Na}_{2} \mathrm{HPO}_{4}, 2 \mathrm{mM}$ EDTA) for $1 \mathrm{~h}$. Insoluble cell debris was pelleted by centrifugation $\left(10,000 \times \mathrm{g}, 10 \mathrm{~min}, 4^{\circ} \mathrm{C}\right)$ and protein concentration of the supernatant was determined using the Bradford assay. $20 \mu \mathrm{g}$ of solubilized protein was then used with the ProFluor Src-Family Kinase Assay (Promega) and assayed according to the manufacturer's instructions.

\subsection{Statistical analysis}

Statistical significance of data was calculated using paired Student's $t$-test or, in case of $n=3$, the Mann-Whitney-U test. Significance was assumed at $\mathrm{p}<0.05$ and is indicated in the figures by asterisks as follows: ${ }^{*}, \mathrm{p}<0.05 ;{ }^{* *}, \mathrm{p}<0.01 ;{ }^{* * *}, \mathrm{p}<0.001$. The propagation of error for independent experiments was calculated based on the Gaussian error propagation law.

\section{Results}

In the course of a recent analysis of PB effects on calpain expression and activity it has been reported that $\mathrm{PB}$ inhibits $\beta$-catenin signaling in mouse hepatoma cells in vitro (Groll et al., 2016a). Neither a comprehensive description nor a mechanistic interpretation of this phenomenon has been published in the literature. It has also recently been shown that the outgrowth of $\beta$-catenin-driven HCC is reduced by PB in a mouse model of HCC (Braeuning et al., 2016). This was now followed up in order to investigate the previously observed $\beta$-catenin-inhibitory effect of PB in depth and to elucidate the underlying molecular mechanisms. The 70.4 mouse hepatoma cell model has previously been used in the recent study by Groll et al. (2016a) and has also been successfully used in further previous studies of $\beta$-catenindependent signaling in mouse hepatoma cells (Braeuning et al., 2007; Zeller et al., 2012). We first characterized the cellular responses to $\mathrm{PB}$ with regard to $\beta$-catenin protein levels. As 70.4 cells possess only low basal activity of the $\beta$-catenin pathway and do not respond to stimulation of the pathway with the physiological agonist Wnt3a, most likely due to a lack of expression of the respective receptor, signaling through $\beta$-catenin was activated in the cells by $1 \mu \mathrm{M}$ of the proteasome inhibitor MG132 which leads to elevated levels of $\beta$-catenin by impeding its degradation (cp. Groll et al. (2016a)).

\subsection{PB inhibits $\beta$-catenin accumulation, nuclear translocation, and transcriptional activity}

Immunocytochemical staining revealed that $\beta$-catenin was mostly localized at the cell membrane in untreated cells, whereas incubation with $1 \mu \mathrm{M}$ MG132 for $24 \mathrm{~h}$ induced massive cellular $\beta$-catenin accumulation and nuclear translocation (Fig. 1A), thus representing a suitable in vitro correlate to the massive accumulation of $\beta$-catenin in vivo in murine HCC (Braeuning et al., 2016). When the $\beta$-catenin-activated 70.4 cells were now treated with $\mathrm{PB}$ in order to mimic the PB effect on $\beta$-catenin-activated HCC in vivo, the accumulation of $\beta$-catenin, however, appeared to be reduced in the presence of $3 \mathrm{mM}$ PB (Fig. 1A). Time-resolved Western blot analysis of $\beta$-catenin protein levels revealed an increase following treatment with MG132, along with the appearance of a second band with slightly higher molecular weight representing ubiquitinylated $\beta$-catenin which was no more degraded in the proteasome (Fig. 1B). The increase observed after MG132 treatment was significantly counteracted by PB (Fig. 1B-C). This observation was substantiated by detailed time-resolved analyses of the differently phosphorylated versions of $\beta$-catenin (Fig. 2A-F), demonstrating that PB approximately halved the MG132-mediated increase of the different phospho-forms of $\beta$-catenin. Similarly, the interaction of free cellular $\beta$-catenin with its known binding partners GST-ICAT, GST-ECT, and GST-TFC4 was measured as a surrogate for the cellular amount of free, transcriptionally active $\beta$-catenin and found to be increased by treatment with MG132, an effect which was again bisected in size by PB (Fig. 2G-I). The latter protein-protein interactions were not altered by $\mathrm{PB}$ if recombinant $\beta$-catenin was incubated with its immobilized interaction partners in the presence of increasing concentrations of $\mathrm{PB}$ (up to $30 \mathrm{mM}$ ), indicating that $\mathrm{PB}$ does not directly interfere with the analyzed protein-protein interactions of $\beta$-catenin and that the assays were not disturbed by direct effects of $\mathrm{PB}$. Results confirmed that the drug did not directly affect binding of $\beta$-catenin to its partners (Appendix, Supplementary Fig. 1). Taken together, these data indicate that PB reduces the expected MG132-induced increase in $\beta$-catenin protein amounts and especially of free, transcriptionally active $\beta$-catenin, which might result in reduced activity of Wnt/ $\beta$-catenin signaling.

Effects of PB on the $\beta$-catenin pathway were thus verified using a luciferase reporter system driven by an array of 8 binding sites for $\beta$-catenin/TCF (SuperTopFlash reporter, STF) and stably transfected into 70.4 cells (Braeuning et al., 2007; Groll et al., 2016a). Using MG132 or the alternative proteasome inhibitor bortezomib, the reporter was dramatically induced by approximately 500 -fold. Following co-treatment of cells with a proteasome inhibitor and $3 \mathrm{mM} \mathrm{PB}$, only about half of the induction caused by the proteasome inhibitors alone was measured, which was a statistically significant reduction of the proteasome inhibitor effect (Fig. 3A). PB was also able to statistically significant reduce basal activity (i.e., in the absence of an inducer of the pathway) of Wnt/ $\beta$-catenin signaling by $\sim 50 \%$ (Fig. $3 \mathrm{~A}$ ). Inhibition of the STF reporter by PB was verified using a total of 6 different stably STFtransfected 70.4-derived cell clones (not shown). All depicted data stem from the same cell line as used in Groll et al. (2016a) and also previously employed in Braeuning et al. (2007). In order to switch to a less unspecific way of $\beta$-catenin activation than proteasome 
inhibition, $\mathrm{LiCl}$ was used at a concentration of $15 \mathrm{mM}$. $\mathrm{LiCl}$ is frequently used as an inhibitor of GSK3 $\beta$ and thereby inducer of $\beta$-catenin protein stability and signaling (e.g. see its use on 70.4 cells in Braeuning et al. (2007)). $\mathrm{LiCl}$ activated the STF reporter more moderately ( $\sim 14$-fold) than the proteasome inhibitors, whereby activation was almost entirely blocked by PB with high statistical significance (Fig. 3B). Inhibition of LiCl-induced STF reporter signals by $\mathrm{PB}$ was clearly concentration-dependent (Fig. 3B) and the degree of inhibition at $3 \mathrm{mM}$ PB was comparable to $20 \mu \mathrm{M}$ of the model $\beta$-catenin/TCF inhibitor iCRT3 (Appendix, Supplementary Fig. 2). Similar to what was observed in 70.4 cells, inhibition of the STF reporter signal by PB was also observed in Hepa1c1c7 and 55.1c mouse hepatoma, as well as in HepG2 human hepatoma cells (not shown), indicating that the observed inhibition of $\beta$-catenin by PB is not restricted to the 70.4 model.

\section{2. $\beta$-catenin inhibition by is independent of known mediators of hepatic PB effects}

To firmly exclude involvement of the well-known cytosolic $\beta$-catenin degradation complex in the inhibition of $\beta$-catenin signaling by $\mathrm{PB}$, a 70.4-derived subclone allowing for doxycyclinedependent expression of mutant, constitutively active $\beta$-catenin $^{\text {S33Y }}$ (Zeller et al., 2012) was used in an additional experiment. The mutant $\beta$-catenin ${ }^{\mathrm{S3} 3 \mathrm{Y}}$ is resistant against degradation via the cytosolic degradation complex. As shown in Fig. 3C, $3 \mathrm{mM}$ PB significantly inhibited basal and $\beta$-catenin ${ }^{\mathrm{S} 33 \mathrm{Y}}$-induced STF reporter activities, demonstrating that $\beta$-catenin inhibition by PB is independent of the degradation complex. Inhibition of $\beta$-catenin signaling was further confirmed at the mRNA level using the model $\beta$-catenin target gene Axin2 as a surrogate for cellular $\beta$-catenin transcriptional activity: basal Axin2 expression was significantly inhibited by PB (Fig. 3D). Treatment with $\mathrm{LiCl}$ alone resulted in an approximately 4-fold induction of Axin2 mRNA, which was almost completely blocked by PB (Fig. 3D).

$\mathrm{PB}$ affects hepatocytes by activating CAR and besides CAR activation, PB-mediated effects on liver cells are also connected to Cx32 (see Section 1). We therefore analyzed whether CAR or Cx32 might be involved in the repression of $\beta$-catenin signaling by $\mathrm{PB}$. However, CAR was barely detectable at the mRNA level in 70.4 cells and the model CAR targets Cyp2b10 and Cyp2c, physiologically regulated by $\mathrm{PB}$ hepatocytes in vivo, were not induced in 70.4 cells upon PB treatment, indicating a lack of functional CAR in 70.4 cells (Appendix, Supplementary Fig. 3A). Accordingly, another model CAR agonist, TCPOBOP, did not affect basal or LiCl-induced STF reporter activities in a PB-like manner (Appendix, Supplementary Fig. 3B). Similarly, treatment with the CAR agonist PCB153 did also not mimic the activity of PB on STF reporter activities (not shown). Cx32 mRNA expression was also barely detectable in 70.4 cells (Appendix, Supplementary Fig. 3A) and accordingly, Cx32 protein was not detectable by Western blotting or immunostaining (not shown). Moreover, $\beta$-catenin inhibition by PB was also effective at

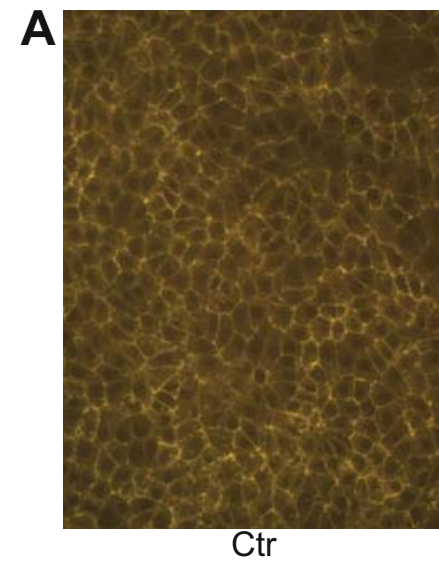

B

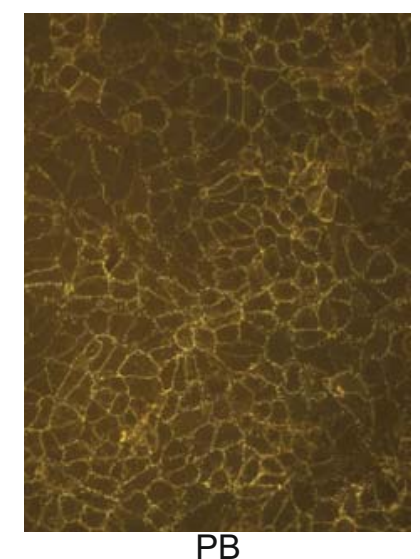

PB

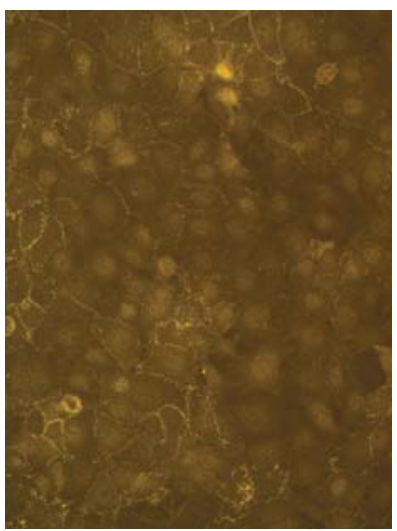

MG132

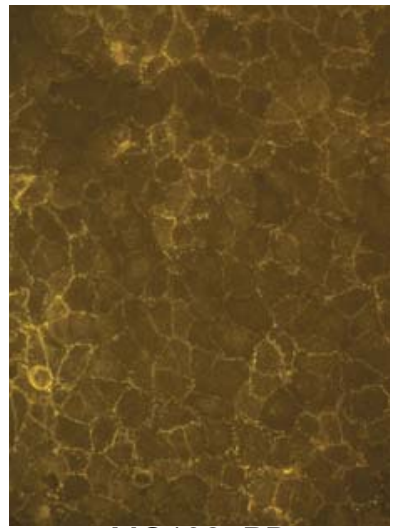

MG132+PB

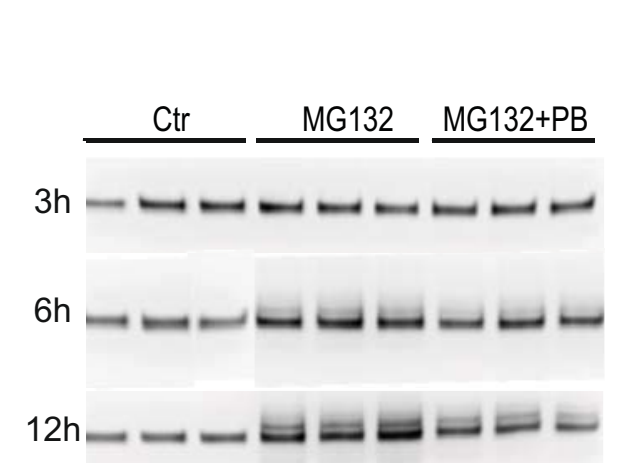

C

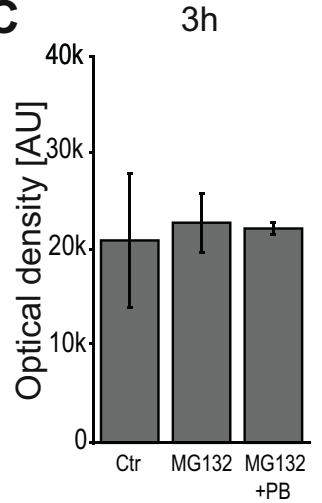

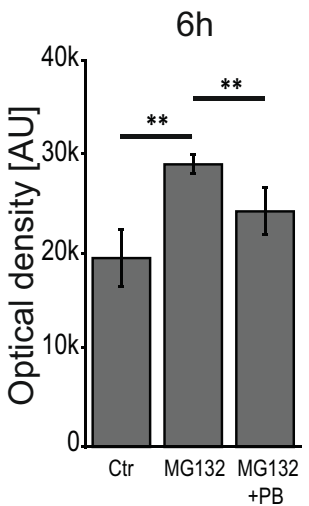

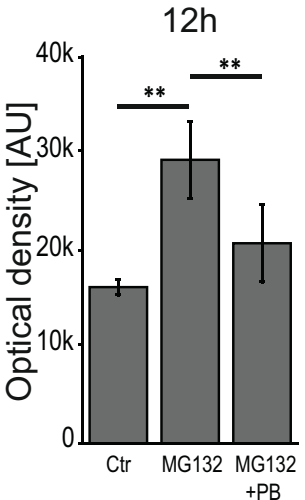

Fig. 1. Phenobarbital (PB) blocks $\beta$-catenin accumulation and nuclear translocation in 70.4 mouse hepatoma cells. (A) 70.4 cells incubated with $0.1 \%$ DMSO (solvent control, Ctr.), PB ( $3 \mathrm{mM})$, the proteasome inhibitor and $\beta$-catenin inducer MG132 $(1 \mu \mathrm{M})$, or a combination of PB and MG132 for $24 \mathrm{~h}$. Immunostaining was carried out using an antibody against $\beta$-catenin together with a Cy3-labeled secondary antibody. Under normal conditions, $\beta$-catenin is mostly present at the cell membranes. Activation of the pathway via the inhibition of $\beta$-catenin degradation by MG132 leads to cytoplasmic accumulation and nuclear translocation of $\beta$-catenin. This process is counteracted by simultaneous incubation with MG132 and PB. (B) Western blotting analysis of $\beta$-catenin levels in 70.4 cells, with or without addition of MG132, or MG132 and PB. The timedependent increase in $\beta$-catenin protein levels by MG132 is counteracted by PB. Representative images (out of $n=3$ ) are shown. Please note the formation of a second band of higher molecular weight representing ubiquitinylated $\beta$-catenin. (C) Densitometric analysis of Western blotting data. Statistical significance (Mann-Whitney-U-test) is indicated by asterisks: *, p $<0.05$; ${ }^{* *}, \mathrm{p}<0.01$; $^{* * *}, \mathrm{p}<0.001$. 
A

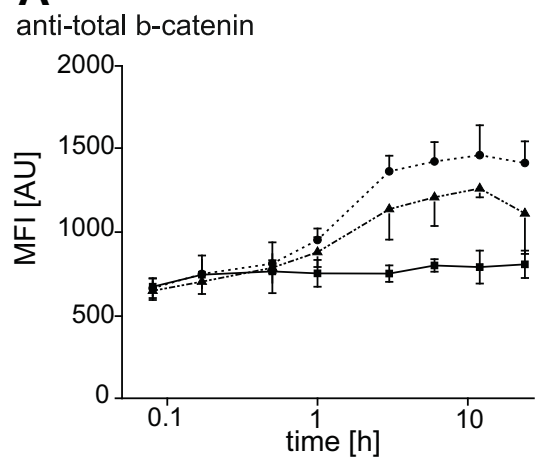

D

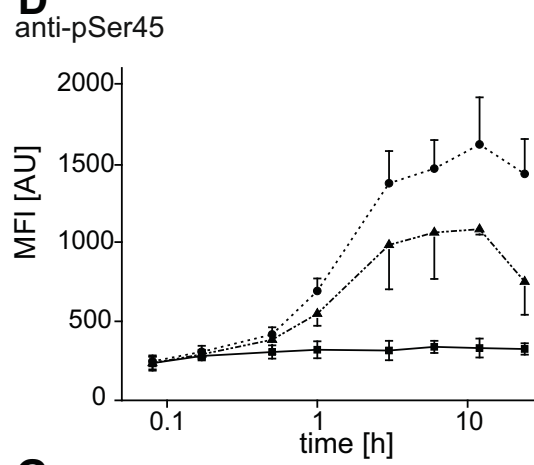

G

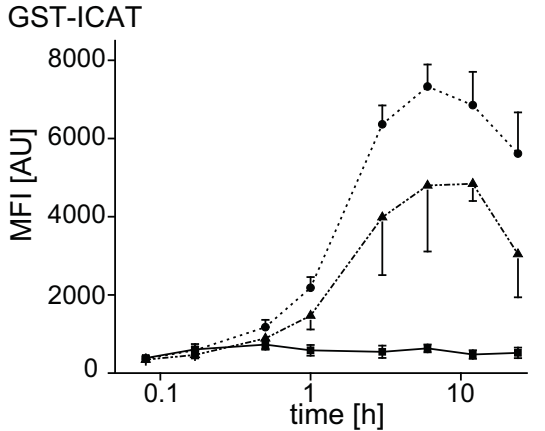

B

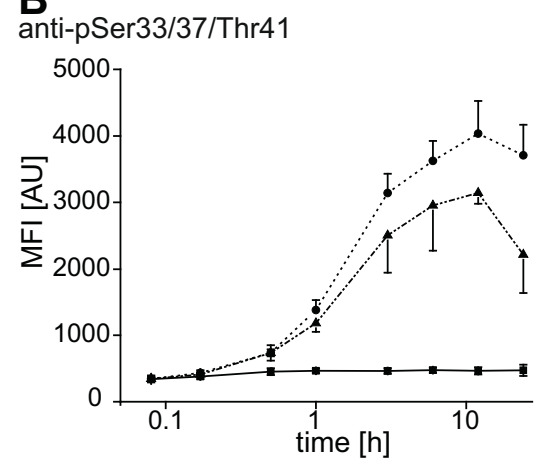

E

anti-pSer552

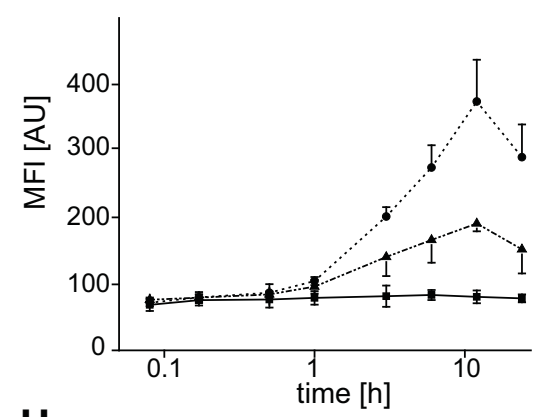

H

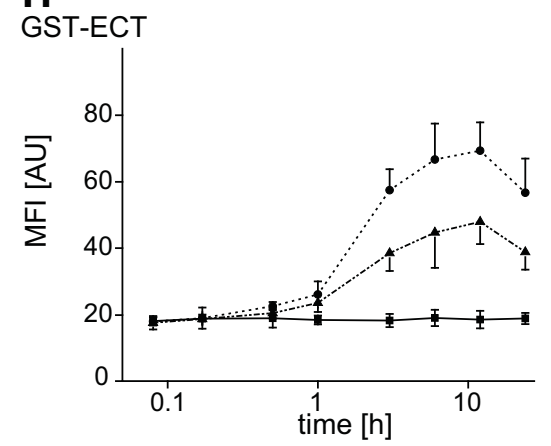

C

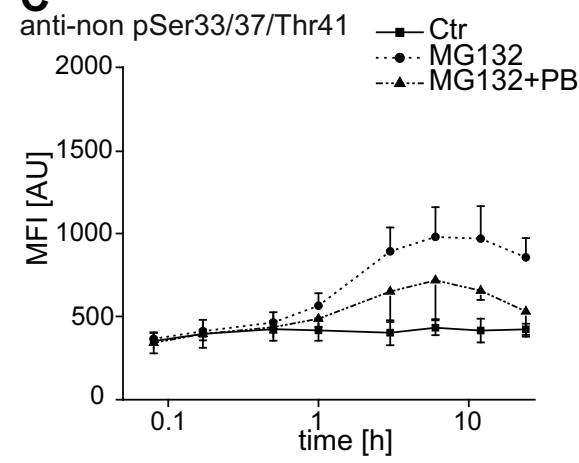

F

anti-pSer675

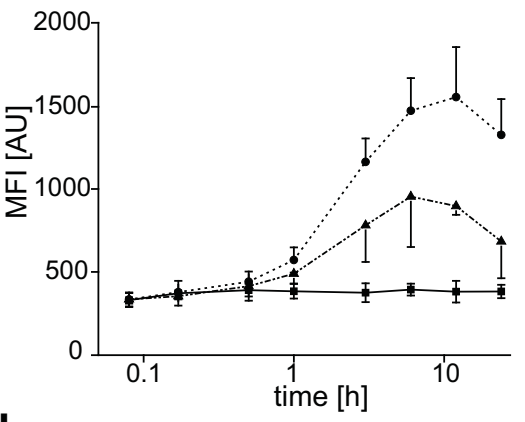

I

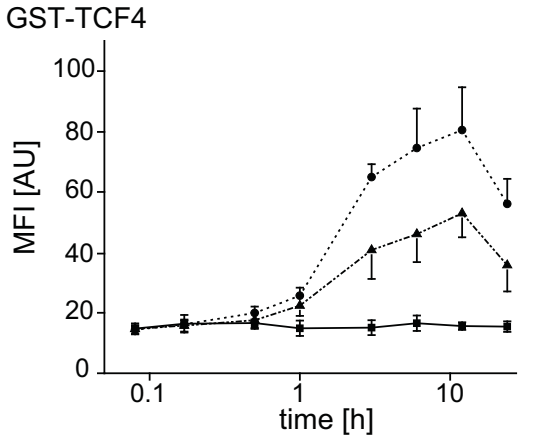

Fig. 2. Time-resolved analysis of different post-translational modifications of $\beta$-catenin and of $\beta$-catenin interaction with known binding partners in 70.4 mouse hepatoma cells, as detected by microsphere-based sandwich immunoassays. Cells were incubated for the indicated periods of time in the presence of $0.1 \%$ DMSO (solvent control; Ctr.), MG132 $(1 \mu \mathrm{M})$ or MG132 and PB $(1 \mu \mathrm{M}$ and $3 \mathrm{mM}$, respectively). Different $\beta$-catenin modifications were detected using a microsphere-based approach as described in the Materials and Methods section. The assays were conducted with appropriate antibodies against different versions of $\beta$-catenin or with GST fusion proteins of known $\beta$-catenin interaction partners used as bait proteins to detect free transcriptionally active $\beta$-catenin. The following $\beta$-catenin species were detected: (A) total $\beta$-catenin, (B) $\beta$-catenin phospho-Ser33/Ser37/Thr41, (C) $\beta$-catenin non-phospho-Ser33/Ser37/Thr41, (D) $\beta$-catenin phospho-Ser45, (E) $\beta$-catenin phospho-Ser552, (F) $\beta$-catenin phosphoSer675, (G) interaction of free $\beta$-catenin with ICAT (GST-ICAT fusion protein), (H) interaction of free $\beta$-catenin with E-cadherin (GST-ECT), (I) interaction of free $\beta$-catenin with TCF4 (GST-TCF4). Activation of $\beta$-catenin signaling by MG132 leads to an increase in all $\beta$-catenin species analyzed, which is diminished by simultaneous treatment of cells with PB. Interaction of $\beta$-catenin with the known interaction partners GST-ICAT, GST-ECT, and GST-TCF4 is influenced in a similar manner, indicating an increase of free, transcriptionally active $\beta$-catenin by MG132 and a reduction by PB. Mean $+/-\operatorname{SD}(n=3)$ is shown.

very low density ( $<20 \%$ confluency) of 70.4 cells, where cell-cell contacts are not expected to play a major role (not shown). The inhibitory effect of $\mathrm{PB}$ on the $\beta$-catenin signaling pathway is thus independent of CAR and Cx32, the known mechanisms by which PB is generally thought to affect hepatic cells.

Antiepileptic properties of PB are linked to its allosteric activity at the $\mathrm{GABA}_{\mathrm{A}}$ receptor (Macdonald and McLean, 1986) and interference with the $\mathrm{GABA}_{\mathrm{A}}$ receptor in the presence of GABA might therefore in principle mediate the effect of $P B$ on $\beta$-catenin. Even though the presence of a functional $\mathrm{GABA}_{\mathrm{A}}$ receptor has not been reported for hepatocyte-derived cell lines, inhibition of the $\beta$-catenin pathway was thus also investigated in serum-free cell culture to ensure the absence of GABA in the system, which might be present at low levels in serum. This change in cell culture conditions did not impact on the effect of PB on $\beta$-catenin activity, as measured via the STF reporter assay (Appendix, Supplementary Fig. 4). Furthermore, addition of $10 \mu \mathrm{M}$ GABA, the physiological agonist of the $\mathrm{GABA}_{\mathrm{A}}$ receptor, to the cell culture medium did not mimic the activity of PB on basal or LiCl-induced STF luciferase reporter signals (Appendix, Supplementary Fig. 4). This indicates that the $\mathrm{GABA}_{\mathrm{A}}$ receptor does not play a role in the inhibition of the $\beta$-catenin pathway by $\mathrm{PB}$.

As PB has been described as an inhibitor of calpains and since calpains are known modulators of $\beta$-catenin stability (Groll et al., 2016a), the calpain inhibitors BAPTA/AM, PD150606, and Calpain Inhibitor IX, were used in order to test whether calpain inhibition would mimic the effects of PB on $\beta$-catenin signaling (cp. Groll et al. (2016a) for proof of successful inhibition of calpain activity by 
A

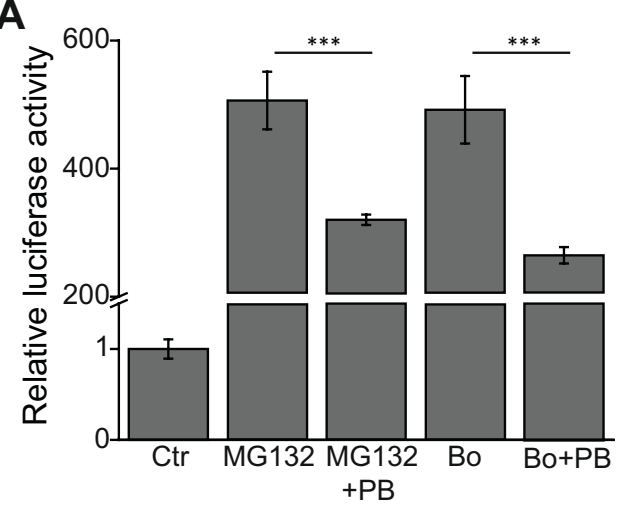

C

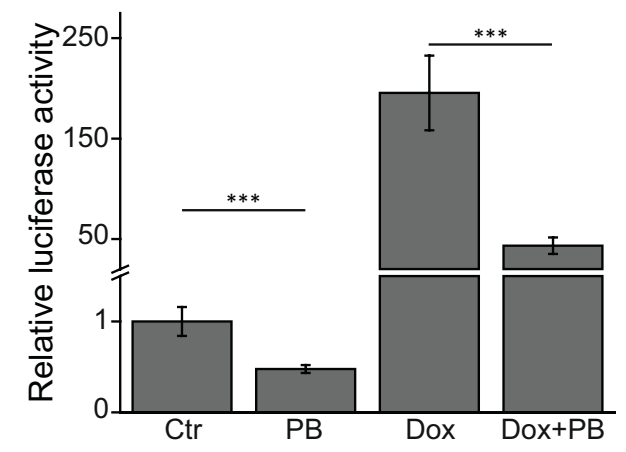

B

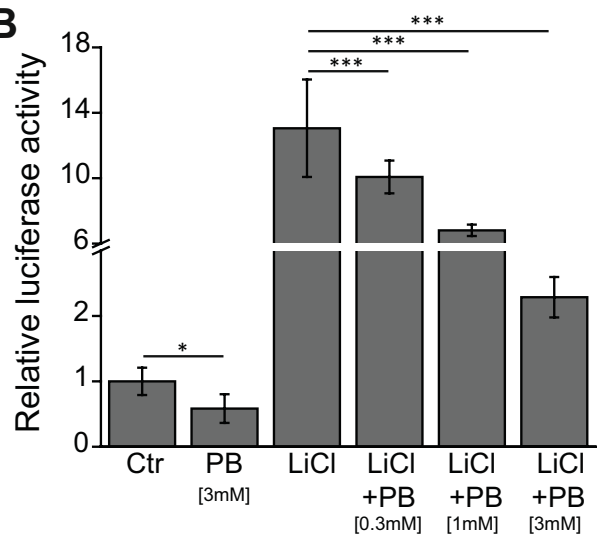

D

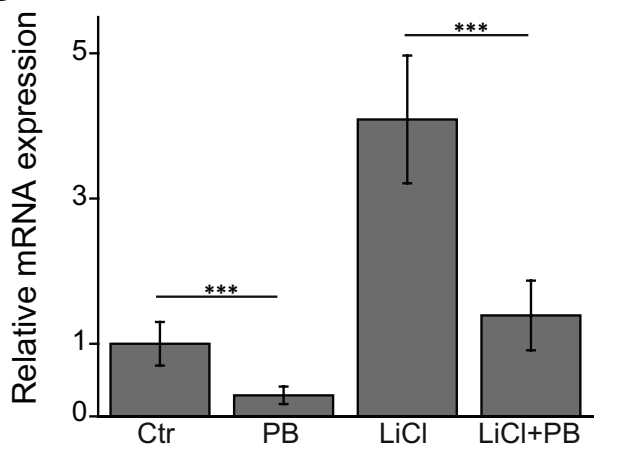

Fig. 3. Inhibition of Wnt/ $\beta$-catenin signaling in 70.4 cells treated with $3 \mathrm{mM}$ PB for $24 \mathrm{~h}(\mathrm{~A})$ Luciferase activities from the $8 \mathrm{x} \beta$-catenin/TCF-driven Supertopflash (STF) reporter vector are increased by treatment with the proteasome inhibitors MG132 (1 $\mu \mathrm{M})$ or bortezomib (Bo; $5 \mu \mathrm{M})$, which impede $\beta$-catenin degradation. This increase is significantly diminished in the presence of PB. (B) Similarly, the more specific induction of $\beta$-catenin signaling by the glycogen synthase kinase $3 \beta$ inhibitor LiCl ( $15 \mathrm{mM}$ ) is blocked by PB in a concentration-dependent manner. (C) Induction of $\beta$-catenin signaling by doxycycline (Dox; $1 \mu \mathrm{g} / \mathrm{mL}$ )-dependent expression of mutant, constitutively active human $\beta$-catenin ${ }^{\mathrm{S3} 3 \mathrm{Y}}$ is also counteracted by PB. (D) Inhibition of $\beta$-catenin signaling by PB was confirmed at the mRNA level using real-time RT-PCR analyses of expression of the endogenous model $\beta$-catenin target gene Axin2 as readout. Control cells (Ctr.) received $0.1 \%$ DMSO (solvent control) or 15 mM aqueous NaCl solution (ionic control for $\mathrm{LiCl}$ treatment). Mean $\pm \mathrm{SD}$ ( $\mathrm{n}>3$ independent experiments; each experiment performed in triplicates or quadruplicates) are shown. Statistical significance (Student's $t$-test) is indicated by asterisks: *, $\mathrm{p}<0.05$; $^{* *}, \mathrm{p}<0.01$; $^{* * *}, \mathrm{p}<0.001$.

BAPTA/AM in 70.4 cells). However, basal as well as LiCl-induced STF reporter activities were not significantly affected by the three different calpain inhibitors (Fig. 4), indicating that calpains also do not play a major role in the inhibition of $\beta$-catenin signaling by PB.

\subsection{PB inhibition of $\beta$-catenin signaling involves EGFR and Src kinase}

It has furthermore been reported that PB has an influence on the activity of Src kinase via inhibition of the EGFR, followed by
A

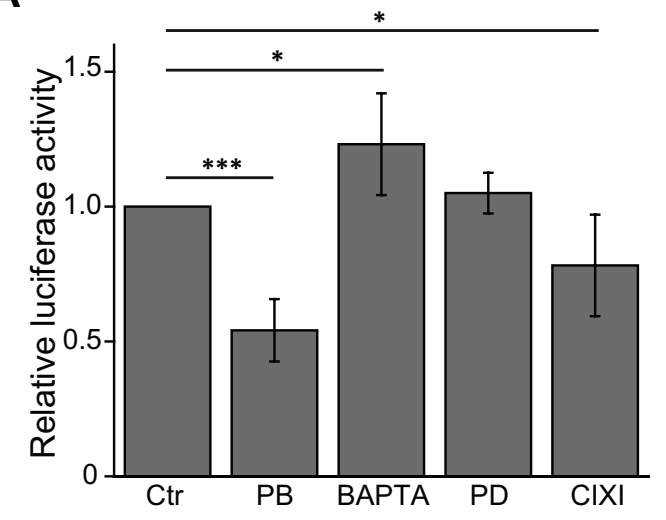

B

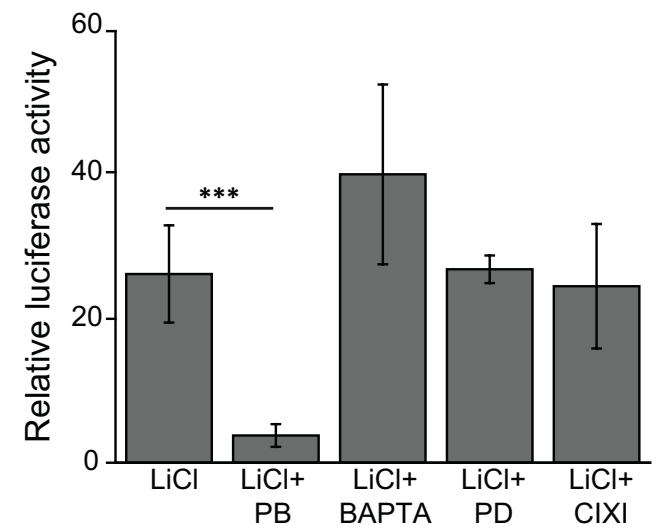

Fig. 4. Calpain inhibition does not mimic the PB effect on $\beta$-catenin signaling, as measured after $24 \mathrm{~h}$ of incubation in 70.4 cells by use of the $8 \times$ $\beta$-catenin/TCF-driven Supertopflash (STF) reporter vector. (A) Reduction of basal STF reporter activity is observed after treatment with $3 \mathrm{mM} P B$, but not after treatment with the calpain inhibitors BAPTA/AM (BAPTA; $2.5 \mu \mathrm{M}$ ), PD150606 (PD; $25 \mu \mathrm{M}$ ), or Calpain inhibitor XI (50 $\mu \mathrm{M}$; CIXI). (B) Calpain inhibitors did also not significantly impact on LiCl (15 mM)-induced STF reporter activity. Control cells (Ctr.) were incubated in the presence of $0.1 \%$ DMSO and $15 \mathrm{mM} \mathrm{NaCl}$. Mean $\pm \mathrm{SD}$ ( $\mathrm{n} \geq 3$ independent experiments; each experiment performed in triplicates or quadruplicates) are shown. Statistical significance (Student's $t$-test) is indicated by asterisks: ${ }^{*}, \mathrm{p}<0.05 ;{ }^{* *}, \mathrm{p}<0.01 ;{ }^{* * *}, \mathrm{p}<0.001$. 
inhibition of Src and PP2A activation. Thus, 70.4 cells were incubated with inhibitors of EGFR and Src in order to check for a possible role of the two proteins in PB-mediated $\beta$-catenin inhibition. As visualized in Fig. 5, chemical inhibition of EGFR by $2 \mu \mathrm{M}$ gefitinib or erlotinib as well as of Src kinase by $10 \mu \mathrm{M}$ Src Kinase Inhibitor I or by $10 \mu \mathrm{M}$ of the alternative Src inhibitor saracatinib was able to suppress basal as well as LiCl-induced $\beta$-catenin-dependent luciferase reporter activities similar to what had been observed with PB. Inversely, two different expression vectors encoding either mouse wildtype or mutated (R177A for enhanced basal activity) Src kinase were equally able to increase the $\beta$-catenin-dependent reporter signal when transfected into 70.4 cells (Fig. 5C). Even more interesting, Src transfection significantly counteracted the effects of PB on $\beta$-catenin signaling (Fig. 5C). PB also significantly reduced total cellular Src kinase activity by approximately 20\% (Fig. 5D). Please note that the commercially available Src kinase assay targets the whole Src kinase family which might lead to an underestimation of an alteration of a single specific kinase from this family, which is influenced by a test substance such as PB. Cell treatment with $10 \mathrm{nM}$ of the PP2A inhibitor okadaic acid did not impact on the inhibition of $\beta$-catenin signaling by $\mathrm{PB}$ (not shown). Altogether, data suggest that $\mathrm{PB}$ inhibits $\beta$-catenin signaling most likely via EGFR and Src, but not further via PP2A and CAR.

\section{4. $P B$ inhibits $\beta$-catenin protein synthesis}

Inhibition of $\beta$-catenin signaling might be either due to diminished production of the protein, or a consequence of accelerated degradation. As the inhibitory effect of PB was preserved when degradation-resistant mutant $\beta$-catenin was expressed in the cells, when calpain proteases were inhibited, or when $\beta$-catenin degradation was blocked by inhibition of the proteasome or GSK3 $\beta$, we suspected that decreased synthesis of $\beta$-catenin in the presence of PB might underlie the observed effect. On the one hand, altered Ctnnb1 (encoding $\beta$-catenin) mRNA transcription has been reported to be involved in altered $\beta$-catenin signaling in smooth muscle cells (Gosens et al., 2010). On the other
A

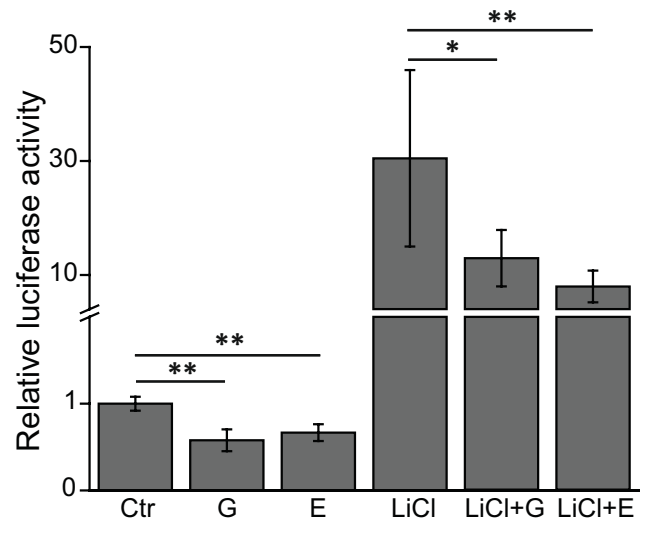

C

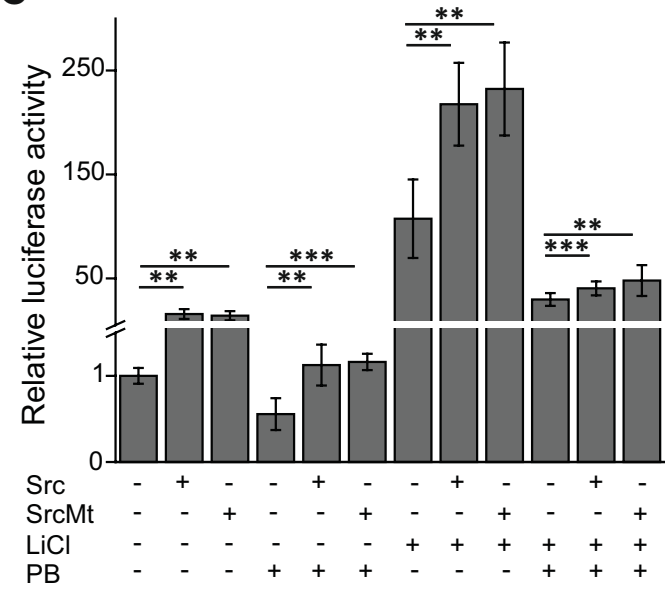

B

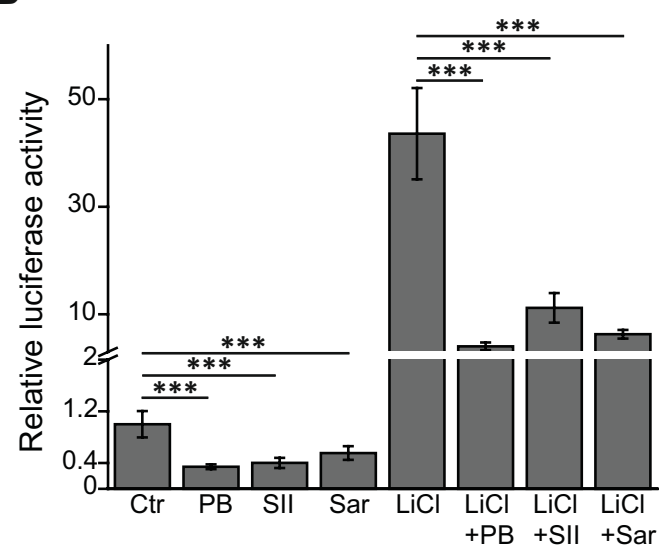

D

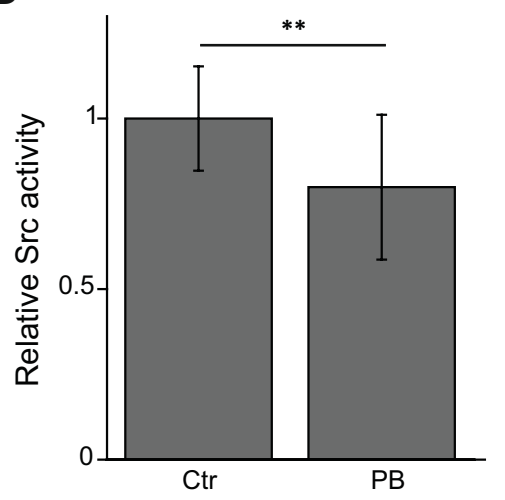

Fig. 5. The inhibitory effect of PB on $\beta$-catenin signaling is mediated via EGFR and Src kinase, as measured after $24 \mathrm{~h}$ of incubation in 70.4 cells by use of the $8 \times$ x-catenin/TCFdriven Supertopflash (STF) reporter vector or a Src family kinase activity assay. (A) Treatment with $2 \mu M$ of the EGFR inhibitors gefitinib (G) or erlotinib (E) suppresses basal as well as $\mathrm{LiCl}(15 \mathrm{mM})$-induced STF reporter signals comparable to what has been observed with PB. (B) Similarly, reduction of basal and LiCl-induced STF reporter signals is recorded when the Src kinase inhibitors Src Kinase Inhibitor I (SII; $10 \mu \mathrm{M}$ ) or saracatinib (Sar; $10 \mu \mathrm{M}$ ) are applied. (C) Inversely, expression of mouse Src kinase from two different expression vectors (wildtype Src (Src) or mutant (R177A) Src (SrcMt)) increases basal and LiCl-induced STF reporter signals. The inhibition of the basal or LiClinduced $\beta$-catenin-dependent reporter signal by treatment with PB ( $3 \mathrm{mM})$ is counteracted by transfection of Src kinase expression vectors. Controls were transfected with empty expression vector backbone. (D) Total cellular Src kinase family activity is reduced in 70.4 cells treated with PB. Data are presented relative to untreated cells. Mean \pm SD ( $\mathrm{n}>3$ independent experiments; each experiment performed in triplicates or quadruplicates) are shown. Statistical significance (Student's $t$-test) is indicated by asterisks: *, $\mathrm{p}<0.05 ;{ }^{* *}, \mathrm{p}<0.01 ;{ }^{* * *}, \mathrm{p}<0.001$. 
hand, Src kinase is capable of interfering with Ctnnb1 mRNA translation into proteins thus regulating $\beta$-catenin signaling via altered translation of the protein (Karni et al., 2005). A possible effect of PB on the expression of Ctnnb1 mRNA in 70.4 cells was investigated first. Treatment with $3 \mathrm{mM} \mathrm{PB}$, however, did not affect Ctnnb1 mRNA levels (Fig. 6A). In a subsequent experiment, translation of $\beta$-catenin was blocked in 70.4 cells by incubation of cells with $0.33 \mu \mathrm{M}$ cycloheximide prior to addition of $3 \mathrm{mM} \mathrm{PB}$ to the culture medium. Cellular amounts of total $\beta$-catenin were determined using a microsphere-based approach. As expected, a decrease in cellular levels of $\beta$-catenin was observed following treatment with the ribosome inhibitor cycloheximide (Fig. 6B). No additional decrease was visible when PB was applied to the cells together with cycloheximide (Fig. 6B). In a final experiment, we performed stable isotope labeling of newly synthesized proteins in 70.4 cells in order to determine the rate of $\beta$-catenin synthesis. De novo $\beta$-catenin synthesis was compared in 70.4 cells treated either with $1 \mu \mathrm{M}$ MG132 to activate $\beta$-catenin signaling or with MG132 and $3 \mathrm{mM}$ PB. These conditions were chosen in order to cover two conditions where a very pronounced effect of PB on $\beta$-catenindependent signaling had been observed in earlier experiments (Figs. 1 and 2). As shown in Fig. 6C, synthesis of $\beta$-catenin was approximately 35\% lower in PB-treated cells $6 \mathrm{~h}$ after addition of $\mathrm{PB}$. This effect was transient, as evidenced by a recovery of the $\beta$-catenin synthesis rate in PB-treated cells to a rate comparable to that of untreated cells at $24 \mathrm{~h}$ after the start of treatment.

\section{Discussion}

The present data show that PB inhibits signaling through the oncogenic $\beta$-catenin signaling pathway in hepatoma cells. While $\beta$-catenin inhibition by PB has been mentioned as a secondary finding in a single previous publication (Groll et al., 2016a), this is the first study which provides an in-depth characterization of the phenomenon and provides insight into the underlying molecular mechanisms.

The inhibitory effect of $\mathrm{PB}$ on $\beta$-catenin was shown to be independent of the nuclear receptor CAR and also independent of the cell-cell communication protein $\mathrm{Cx} 32$, two major players involved in the tumor-promoting effects of $\mathrm{PB}$ in rodents (Moennikes et al., 2000; Yamamoto et al., 2004). PB acts on $\beta$-catenin also independent of the $\mathrm{GABA}_{\mathrm{A}}$ receptor which mediates the pharmacological effects of the barbiturate in the central nervous system (Macdonald and McLean, 1986). Moreover, inhibition of calpains does not seem to play a major role, even though these proteases are regulated by PB (Groll et al., 2016a) and generally capable of regulating $\beta$-catenin activity (Abe and Takeichi, 2007). The regulation of $\beta$-catenin transcriptional activity is mostly regulated by phosphorylation of certain amino acid residues of $\beta$-catenin priming the protein for degradation via the proteasome. Present experiments with mutant $\beta$-catenin ${ }^{\mathrm{S} 33 \mathrm{Y}}$ resistant to phosphorylation of $\beta$-catenin by the cytosolic multiprotein complex, with an inhibitor of GSK3 $\beta$, a key enzyme of this complex, or with inhibitors of the proteasome demonstrate that PB-mediated inhibition of $\beta$-catenin signaling is not mediated via the classic $\beta$-catenin degradation pathway.

Instead, we thought of decreased $\beta$-catenin production in response to cell treatment with $\mathrm{PB}$. As no regulation of $\beta$-catenin was detectable at the mRNA level, a reduced rate of protein synthesis was considered. PB inhibits EGFR and by this way also the multi-functional cellular kinase Src, which in turn affects the activity of PP2A. This mechanism has been proposed to explain the indirect activation of CAR by PB (Mutoh et al., 2013). Data from the literature also convincingly show that Src activity increases the translation of $\beta$-catenin protein at the ribosome (Karni et al., 2005). This is mediated via the MEK/ERK pathway and phosphorylation of eukaryotic initiation factor 4E (Karni et al., 2005). We have now shown that EGFR inhibitors as well as Src inhibitors mimic the inhibitory effect of $\mathrm{PB}$ on $\beta$-catenin signaling, while over-expression of Src kinase counteracts the PB effect. PP2A inhibiton, by contrast, did not impact on $\beta$-catenin signaling in our experiments. This suggested that $\mathrm{PB}$ inhibits the $\beta$-catenin pathway via the inhibition of EGFR and Src, followed by a Srcdownstream mechanism other than through PP2A and CAR. PB acting through EGFR inhibition on $\beta$-catenin protein synthesis might either act via Src kinase and MEK/ERK, or directly via the MAPK signaling pathway without involvement of Src. The present data demonstrate that the former pathway via Src kinase is involved in the transmission of the PB signal (Fig. 7).

It should be noted that the functionality of EGFR with respect to the induction of phosphorylation of its downstream kinase ERK by the physiological EGFR agonist EGF has been shown in 70.4 cells
A

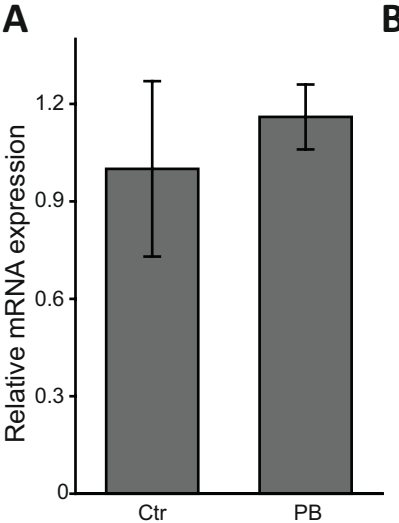

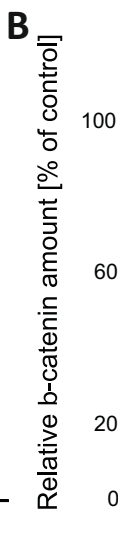
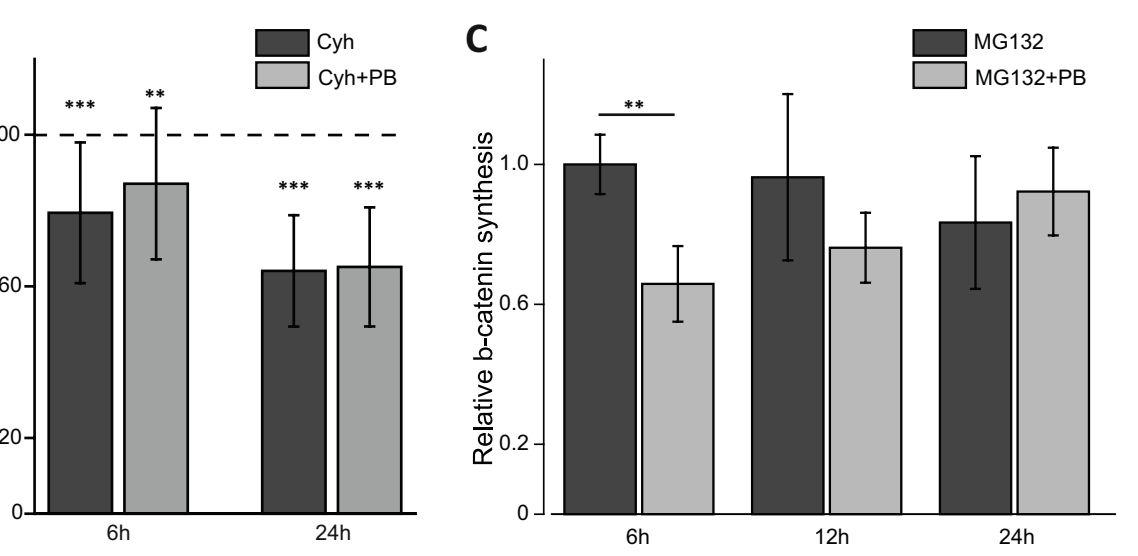

Fig. 6. Altered de novo synthesis of $\beta$-catenin is involved in the inhibition of $\beta$-catenin signaling by PB in 70.4 cells. (A) Transcription of $C$ tnnb1 $\mathrm{mRNA}$ is not inhibited by $3 \mathrm{mM}$ $\mathrm{PB}$ following $24 \mathrm{~h}$ of incubation. (B) Blockade of ribosomal protein synthesis by $0.33 \mu \mathrm{M}$ cycloheximide (Cyh) for the indicated periods of time decreases cellular $\beta$-catenin protein levels, as detected by use of a microsphere-based sandwich immunoassay. A similar reduction is also observed following treatment with 3 mM PB. Of note, no additivity between cycloheximide and PB effects is observed, suggesting a common mechanism of action. (C) A stable isotope labeling approach demonstrates that de novo synthesis of $\beta$-catenin protein is reduced in cells treated with $1 \mu \mathrm{M}$ of the $\beta$-catenin activator MG132 and $3 \mathrm{mM}$ PB, as compared to treatment with MG132 only. Data are presented relative to untreated cells. Mean $\pm \mathrm{SD}(\mathrm{n} \geq 3)$ are shown. Statistical significance (Student's $t$-test) is indicated by asterisks: ${ }^{*}, \mathrm{p}<0.05$; ${ }^{* *}, \mathrm{p}<0.01$; ${ }^{* * *}, \mathrm{p}<0.001$. 


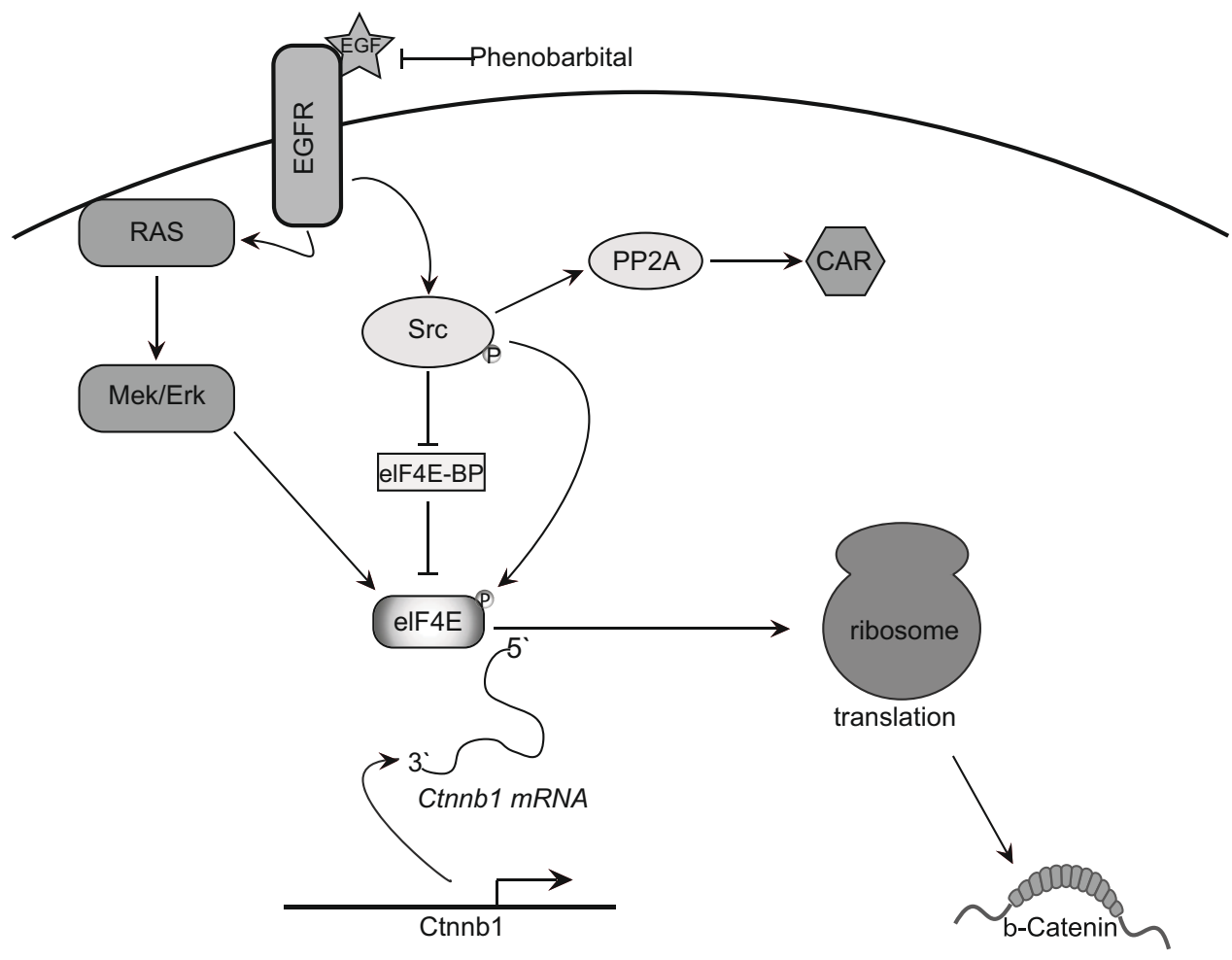

Fig. 7. Schematic representation of putative PB-induced changes in cellular signaling based on the results from the present study and based on previously published results on important players in EGFR- and CAR-dependent effects as well as in the regulation of $\beta$-catenin protein synthesis (Karni et al., 2005; Mutoh et al., 2013). PB inhibits EGFR and thereby subsequently influences Src kinase. Inhibited Src kinase can transmit its signal via PP2A to activate CAR, but is also capable of activating the MEK/ERK pathway leading to altered translation of Ctnnb1 mRNA. Direct signaling from EGFR through RAS to MEK/ERK is also possible. Please also refer to the text of section 4 for further details on experimental evidence for the different steps of signaling depicted in the figure.

before (Braeuning et al., 2007; Zeller et al., 2012). In the course of these analyses, EGF treatment of 70.4 cells has been reported to result in repression of $\beta$-catenin signaling (Braeuning et al., 2007), a finding which at first glance might appear to conflict with present results. Interactions of the $\beta$-catenin and MAPK pathways are generally manifold and complex, involve multiple mutual feedback loops, and are still not fully understood in detail (Zeller et al., 2013). An interesting feature of MAPK signaling is that activation of the same pathway can lead to entirely different, even opposed cellular outcomes, a phenomenon which amongst others critically depends on differences in amplitude and duration of signals through the cascade (Alshamsan, 2011; Bluthgen, 2015; Bluthgen and Legewie, 2008; Kolch et al., 2005). It thus appears plausible that the MAPK pathway behaves strikingly different with regard to its crosstalk with $\beta$-catenin signaling, either following stimulation with EGF causing a strong transient induction of only a few minutes, or following continuous inhibition of EGFR by PB. Another factor which might contribute to the seemingly paradoxical crosstalk between the MAPK and $\beta$-catenin signaling pathways is the complex biology of the EGFR, which activates or inactivates different pathways, depending on the type of activator and on the subsequent fate of the receptor with regard to internalization, intracellular localization and interaction with other signaling proteins (Tomas et al., 2014). Paradoxical activities have also been reported for other signaling pathways. For example, activation of $\beta$-catenin signaling in mouse hepatocytes induces expression of the Cyp2b10 gene (Braeuning et al., 2011). Unexpectedly, expression of Cyp2b10 is also elevated when $\beta$-catenin signaling is silenced in mouse hepatocytes by knockout of Ctnnb1 (Braeuning et al., 2009; Ganzenberg et al., 2013).
The proposed mechanism by which $\mathrm{PB}$ inhibits $\beta$-catenin signaling might be suited to explain the growth inhibition of $\beta$-catenin-activated HCC in APC-deficient mice in the presence of PB. The latter tumors are characterized by strongly elevated levels of Ctnnb1 mRNA along with a deficiency in APC thus impeding $\beta$-catenin degradation (Braeuning et al., 2016). Inhibition of de novo $\beta$-catenin synthesis by PB in such a tumor cell might limit the transcriptional activity of a crucial oncogenic driver cascade and thereby impede growth of the tumor. On the other hand, despite the fact that this topic is not in the major focus of this paper, one might speculate that the more upstream part of the mechanism might be used to explain PB-mediated growth inhibition of tumors which express a mutationally activated RAS protein (Aydinlik et al., 2001; Moennikes et al., 2000). Even though the MAPK is constitutively activated downstream of the EGFR thus making it impossible for $\mathrm{PB}$ to inhibit the pathway by reducing signal transduction through the EGFR/RAS/MEK/ERK axis, EGFR inhibition followed by Src kinase inhibition might again feed into the pathway downstream of the mutant RAS and thus reduce its activity by circumventing the activated oncoprotein. The known transcriptional inhibition of calpains by PB (Groll et al., 2016a) might also be related to the signaling pathways delineated in Fig. 7, as it has been reported that calpain transcription is mediated through the transcription factor AP- 1 , which is amongst others regulated by MAPK signaling (Asangani et al., 2008).

In conclusion, the present data clearly demonstrate an inhibitory effect of $\mathrm{PB}$ on $\beta$-catenin signaling in mouse hepatoma cells in vitro and provide mechanistic insight into the molecular processes underlying this effect. The lowest concentration at which we could observe a significant reduction in the activity of the TCF reporter by PB was $0.3 \mathrm{mM}$ (Li-stimulated cells), equivalent 
to $\sim 70 \mu \mathrm{g} / \mathrm{mL}$. For comparison, the therapeutic steady state serum level of PB as an anticonvulsant in humans is commonly reported as $15-70 \mu \mathrm{g} / \mathrm{mL}$ (e.g. see Houghton et al. (1975)). We are aware of the fact that this comparison does not include potential differences in pharmacokinetic parameters, such as e.g. protein binding, which may cause differences in the free concentrations of the drug between in vivo and in vitro. Based on the present data, however we cannot exclude the possibility that $\beta$-catenin-inhibitory concentrations of PB may be reached in patients. As mentioned in the introduction section, PB inhibits the development of certain liver tumor populations which lack CAR expression, like the hepatoma cells used in the present study. Inhibitory effects mediated by PB might therefore be expected, if present, in those human tissues, where CAR levels are low.

\section{Acknowledgments}

The authors thank Johanna Mahr and Elke Zabinsky for expert technical assistance. The gift of Src kinase expression vectors by Dr. R. Lammers (Tübingen, Germany) and of erlotinib by Dr. M. Toulany (Tübingen, Germany) is greatly acknowledged. This work was funded by the German Federal Ministry of Education and Research (BMBF), grant FKZ 0315742 (Virtual Liver).

\section{Appendix A. Supplementary data}

Supplementary data associated with this article can be found, in the online version, at http://dx.doi.org/10.1016/j.tox.2016.09.018.

\section{References}

Abe, K., Takeichi, M., 2007. NMDA-receptor activation induces calpain-mediated beta-catenin cleavages for triggering gene expression. Neuron 53, 387-397.

Alshamsan, A., 2011. Paradoxical signaling pathways in developing thymocytes. J. Pharm. Pharm. Sci. 14, 378-386.

Asangani, I.A., Rasheed, S.A., Leupold, J.H., Post, S., Allgayer, H., 2008. NRF-1, and AP1 regulate the promoter of the human calpain small subunit 1 (CAPNS1) gene. Gene 410, 197-206.

Aydinlik, H., Nguyen, T.D., Moennikes, O., Buchmann, A., Schwarz, M., 2001. Selective pressure during tumor promotion by phenobarbital leads to clonal outgrowth of beta-catenin-mutated mouse liver tumors. Oncogene 20, 7812-7816.

Bluthgen, N., Legewie, S., 2008. Systems analysis of MAPK signal transduction. Essays Biochem. 45, 95-107.

Bluthgen, N., 2015. Signaling output: it's all about timing and feedbacks. Mol. Syst. Biol. 11, 843.

Braeuning, A., Schwarz, M. 2016. Is the question of phenobarbital as potential liver cancer risk factor for humans really resolved? Arch. Toxicol. 90, 1525-1526.

Braeuning, A., Vetter, S., 2012. The nuclear factor kappaB inhibitor (E)-2-fluoro-4'methoxystilbene inhibits firefly luciferase. Biosci. Rep. 32, 531-537.

Braeuning, A., Menzel, M., Kleinschnitz, E.M., Harada, N., Tamai, Y., Kohle, C., Buchmann, A., Schwarz, M., 2007. Serum components and activated Ha-ras antagonize expression of perivenous marker genes stimulated by beta-catenin signaling in mouse hepatocytes. FEBS J. 274, 4766-4777.

Braeuning, A., Sanna, R., Huelsken, J., Schwarz, M., 2009. Inducibility of drugmetabolizing enzymes by xenobiotics in mice with liver-specific knockout of Ctnnb1. Drug Metab. Dispos. 37, 1138-1145.

Braeuning, A., Kohle, C., Buchmann, A., Schwarz, M., 2011. Coordinate regulation of cytochrome P450 1a1 expression in mouse liver by the aryl hydrocarbon receptor and the beta-catenin pathway. Toxicol. Sci. 122, 16-25.

Braeuning, A., Gavrilov, A., Brown, S., Wolf, C.R., Henderson, C.J., Schwarz, M., 2014 Phenobarbital-mediated tumor promotion in transgenic mice with humanized CAR and PXR. Toxicol. Sci. 140, 259-270.

Braeuning, A., Henderson, C.J., Wolf, C.R., Schwarz, M., 2015. Model systems for understanding mechanisms of nongenotoxic carcinogenesis: response. Toxicol. Sci. 147, 299-300.

Braeuning, A., Gavrilov, A., Geissler, M., Wenz, C., Colnot, S., Templin, M.F., Metzger U., Romer, M., Zell, A., Schwarz, M., 2016. Tumor promotion and inhibition by phenobarbital in livers of conditional Apc-deficient mice. Arch. Toxicol. 90, $1481-1494$.

Braeuning, A., 2014. Liver cell proliferation and tumor promotion by phenobarbital: relevance for humans? Arch. Toxicol. 88, 1771-1772.

Elcombe, C.R., Peffer, R.C., Wolf, D.C., Bailey, J., Bars, R., Bell, D., Cattley, R.C., Ferguson, S.S., Geter, D., Goetz, A., Goodman, J.I., Hester, S., Jacobs, A Omiecinski, C.J., Schoeny, R., Xie, W., Lake, B.G., 2014. Mode of action and human relevance analysis for nuclear receptor-mediated liver toxicity: a case study with phenobarbital as a model constitutive androstane receptor (CAR) activator. Crit. Rev. Toxicol. 44, 64-82.

Ganzenberg, K., Singh, Y., Braeuning, A., 2013. The time point of beta-catenin knockout in hepatocytes determines their response to xenobiotic activation of the constitutive androstane receptor. Toxicology 308, 113-121.

Gosens, R., Baarsma, H.A., Heijink, I.H., Oenema, T.A., Halayko, A.J., Meurs, H. Schmidt, M., 2010. De novo synthesis of \{beta\}-catenin via H-Ras and MEK regulates airway smooth muscle growth. FASEB J. 24, 757-768.

Groll, N., Emele, F., Poetz, O., Rothbauer, U., 2015a. Towards multiplexed proteinprotein interaction analysis using protein tag-specific nanobodies. J. Proteomics 127, 289-299.

Groll, N., Sommersdorf, C., Joos, T.O., Poetz, O., 2015b. A bead-based multiplex sandwich immunoassay to assess the abundance and posttranslational modification state of beta-catenin. Methods Mol. Biol. 1295, 441-453.

Groll, N., Petrikat, T., Vetter, S., Colnot, S., Weiss, F., Poetz, O., Joos, T.O., Rothbauer, U. Schwarz, M., Braeuning, A., 2016a. Coordinate regulation of Cyp2e1 by betacatenin- and hepatocyte nuclear factor 1alpha-dependent signaling. Toxicology 350-352 40-48.

Groll, N., Kollotzek, F., Goepfert, J., Joos, T.O., Schwarz, M., Braeuning, A., 2016b. Phenobarbital inhibits calpain activity and expression in mouse hepatoma cells. Biol. Chem. 397, 91-96.

Houghton, G.W., Richens, A., Toseland, P.A., Davidson, S., Falconer, M.A., 1975. Brain concentrations of phenytoin, phenobarbitone and primidone in epileptic patients. Eur. J. Clin. Pharmacol. 9, 73-78.

IARC, 2001. Phenobarbital and its sodium salt. IARC Monographs on the Evaluation of Carcinogenic Risks to Humans, Vol 79, IARC Press, Lyon, France, pp. 161-288.

Jaworski, M., Buchmann, A., Bauer, P., Riess, O., Schawrz, M., 2005. B-raf and Ha-ras mutations in chemically induced mouse liver tumors. Oncogene 24, 1290-1295.

Jaworski, M., Ittrich, C., Hailfinger, S., Bonin, M., Buchmann, A., Schwarz, M., Kohle, C., 2007. Global gene expression in Ha-ras and B-raf mutated mouse liver tumors. Int. J. Cancer 121, 1382-1385.

Karni, R., Gus, Y., Dor, Y., Meyuhas, O., Levitzki, A., 2005. Active Src elevates the expression of beta-catenin by enhancement of cap-dependent translation. Mol. Cell. Biol. 25, 5031-5039.

Kolch, W., Calder, M., Gilbert, D., 2005. When kinases meet mathematics: the systems biology of MAPK signalling. FEBS Lett. 579, 1891-1895.

Kollmorgen, G., Bossenmaier, B., Niederfellner, G., Haring, H.U., Lammers, R., 2012. Structural requirements for cub domain containing protein 1 (CDCP1) and Src dependent cell transformation. PLoS One 7, e53050.

Kress, S., Konig, J., Schweizer, J., Lohrke, H., Bauer-Hofmann, R., Schwarz, M., 1992. p53 mutations are absent from carcinogen-induced mouse liver tumors but occur in cell lines established from these tumors. Mol. Carcinogenesis 6, 148158.

Luckert, C., Schulz, C., Lehmann, N., Thomas, M., Hofmann, U., Hammad, S., Hengstler, J.G., Braeuning, A., Lampen, A., Hessel, S., 2016. Comparative analysis of 3D culture methods on human HepG2 cells. Arch. Toxicol. doi:http://dx.doi. org/10.1007/s00204-016-1677-z (in press).

Lustig, B., Behrens, J., 2003. The Wnt signaling pathway and its role in tumor development. J. Cancer Res. Clin. Oncol. 129, 199-221.

Macdonald, R.L., McLean, M.J., 1986. Anticonvulsant drugs: mechanisms of action. Adv. Neurol. 44, 713-736.

Moennikes, O., Buchmann, A., Romualdi, A., Ott, T., Werringloer, J., Willecke, K., Schwarz, M., 2000. Lack of phenobarbital-mediated promotion of hepatocarcinogenesis in connexin32-null mice. Cancer Res. 60, 5087-5091.

Mutoh, S., Sobhany, M., Moore, R., Perera, L., Pedersen, L., Sueyoshi, T., Negishi, M., 2013. Phenobarbital indirectly activates the constitutive active androstane receptor (CAR) by inhibition of epidermal growth factor receptor signaling. Sci. Signal. 6, ra31.

Pfaffl, M.W., 2001. A new mathematical model for relative quantification in realtime RT-PCR. Nucleic Acids Res. 29, e45.

Qatanani, M., Moore, D.D., 2005. CAR, the continuously advancing receptor, in drug metabolism and disease. Curr. Drug Metabol. 6, 329-339.

Rignall, B., Grote, K., Gavrilov, A., Weimer, M., Kopp-Schneider, A., Krause, E., Appel, K.E., Buchmann, A., Robertson, L.W., Lehmler, H.J., Kania-Korwel, I., Chahoud, I., Schwarz, M., 2013. Biological and tumor-promoting effects of dioxin-like and non-dioxin-like polychlorinated biphenyls in mouse liver after single or combined treatment. Toxicol. Sci. 133, 29-41.

Schulthess, P., Loffler, A., Vetter, S., Kreft, L., Schwarz, M., Braeuning, A., Bluthgen, N., 2015. Signal integration by the CYP1A1 promoter-a quantitative study. Nucleic Acids Res. 43, 5318-5330.

Schwanhausser, B., Gossen, M., Dittmar, G., Selbach, M., 2009. Global analysis of cellular protein translation by pulsed SILAC. Proteomics 9, 205-209.

Tomas, A., Futter, C.E., Eden, E.R., 2014. EGF receptor trafficking: consequences for signaling and cancer. Trends Cell Biol. 24, 26-34.

Traenkle, B., Emele, F., Anton, R., Poetz, O., Haeussler, R.S., Maier, J., Kaiser, P.D., Scholz, A.M., Nueske, S., Buchfellner, A., Romer, T., Rothbauer, U., 2015. Monitoring interactions and dynamics of endogenous beta-catenin with intracellular nanobodies in living cells. Mol. Cell. Proteomics 14, 707-723.

Weiss, F., Schnabel, A., Planatscher, H., van den Berg, B.H., Serschnitzki, B., Nuessler, A.K., Thasler, W.E., Weiss, T.S., Reuss, M., Stoll, D., Templin, M.F., Joos, T.O., Marcus, K., Poetz, O., 2015. Indirect protein quantification of drug-transforming enzymes using peptide group-specific immunoaffinity enrichment and mass spectrometry. Sci. Rep. 5, 8759.

Whysner, J., Ross, P.M., Williams, G.M., 1996. Phenobarbital mechanistic data and risk assessment: enzyme induction enhanced cell proliferation, and tumor promotion. Pharmacol. Therap. 71, 153-191. 
Yamada, T., Okuda, Y., Kushida, M., Sumida, K., Takeuchi, H., Nagahori, H., Fukuda, T. Lake, B.G., Cohen, S.M., Kawamura, S., 2014. Human hepatocytes support the hypertrophic but not the hyperplastic response to the murine nongenotoxic hepatocarcinogen sodium phenobarbital in an in vivo study using a chimeric mouse with humanized liver. Toxicol. Sci. 142, 137-157.

Yamamoto, Y., Moore, R., Goldsworthy, T.L., Negishi, M., Maronpot, R.R., 2004. The orphan nuclear receptor constitutive active/androstane receptor is essential for liver tumor promotion by phenobarbital in mice. Cancer Res. 64, 7197-7200.
Zeller, E. Mock, K., Horn, M., Colnot, S., Schwarz, M., Braeuning, A., 2012. Dualspecificity phosphatases are targets of the Wnt/beta-catenin pathway and candidate mediators of beta-catenin/Ras signaling interactions. Biol. Chem. 393 $1183-1191$.

Zeller, E., Hammer, K., Kirschnick, M., Braeuning, A., 2013. Mechanisms of RAS/betacatenin interactions. Arch. Toxicol. 87, 611-632. 